\title{
Characteristics of HAM/TSP after kidney transplantation from HTLV-1 positive living donors
}

\author{
Miyuna Kimura ${ }^{*}$, Junji Yamauchi ${ }^{2}$, Hideki Taisho ${ }^{3}$, Tomoo Sato ${ }^{4}$, Naoko Yagishita ${ }^{4}$, Natsumi Araya ${ }^{4}$, Kentaro Sato ${ }^{1}$, \\ Takayuki Kikuchi ${ }^{1}$, Yasuhiro Hasegawa ${ }^{5}$, Tatsuya Chikaraishi ${ }^{6}$, Yuugo Shibagaki ${ }^{2}$, Yoshihisa Yamano ${ }^{4}$ \\ From 17th International Conference on Human Retroviruses: HTLV and Related Viruses \\ Trois Ilets, Martinique. 18-21 June 2015
}

It has been sporadically reported that HTLV-1 associated myelopathy/tropical spastic paraparesis (HAM/ TSP) develops after living-donor kidney transplantation from HTLV-1 positive donors (D+) to negative recipients (R-). However, these details have been unknown. Thus we evaluated the incidence and clinical characteristics of HAM/TSP after living-donor kidney transplantation from $\mathrm{D}+$ to $\mathrm{R}-(\mathrm{D}+\mathrm{R}$-transplantation). Using data obtained from the Japanese Renal Transplant Registry, we analyzed 13,299 cases of living-donor kidney transplantation between 2000 and 2013 in Japan. In addition, we have collected information about 5 patients who developed HAM/TSP after D+R-transplantation. The incidence of HAM/TSP after D+R-transplantation was calculated as the ratio of "the number of recipients who developed HAM/TSP" to "the number of cases of D+Rtransplantation". The characteristics of HAM/TSP in $\mathrm{D}+\mathrm{R}$-transplant recipients such as time from transplantation to disease onset and rate of disease progression are investigated. About $70 \%$ of all 13,299 donors took a HTLV-1 antibody test and 64 cases were positive for HTLV-1 antibody. Although the remaining 4,072 donors didn't take the antibody test, we estimated the number of HTLV-1 positive donors as 36 according to the HTLV-1 prevalence in Japan. As a result, the estimated incidence of HAM/TSP after D+R-transplantation was $5 \%$. All the 5 cases of HAM/TSP after D+R-transplantation showed an early onset after transplantation. Four out of five cases developed rapidly and had difficulty walking in one or two years. This study demonstrated that incidence rate (5\%) of HAM/TSP in recipients after $\mathrm{D}+\mathrm{R}$-transplantation is extremely higher compared to

\footnotetext{
* Correspondence: h23041@marianna-u.ac.jp

'St. Marianna University School of Medicine, Kawasaki, Kanagawa, 2168511, Japan

Full list of author information is available at the end of the article
}

the lifetime risk (0.25\%) of HAM/TSP in an HTLV-1infected person. Further, this study suggested that HAM/TSP after D+R-transplantation is characterized by rapid onset and progression. Therefore, we need to conduct nationwide survey to assess the risk of $D+R$ transplantation.

\section{Authors' details}

'St. Marianna University School of Medicine, Kawasaki, Kanagawa, 2168511, Japan. ${ }^{2}$ Department of Nephrology and Hypertension, St. Marianna University School of Medicine, Kawasaki, Kanagawa, 2168511, Japan. ${ }^{3}$ Taisho Hospital, Kagoshima, Kagoshima, 8900067, Japan. ${ }^{4}$ Department of Rare Diseases Research, Institute of Medical Science, St. Marianna University School of Medicine, Kawasaki, Kanagawa, 2168511, Japan. ${ }^{5}$ Department of Neurology, St. Marianna University School of Medicine, Kawasaki, Kanagawa, 2168511, Japan. ${ }^{6}$ Department of Urology, St. Marianna University School of Medicine, Kawasaki, Kanagawa, 2168511, Japan.

Published: 28 August 2015

\section{doi:10.1186/1742-4690-12-S1-014}

Cite this article as: Kimura et al:: Characteristics of HAM/TSP after kidney transplantation from HTLV-1 positive living donors. Retrovirology 2015 12(Suppl 1):014.

Submit your next manuscript to BioMed Central and take full advantage of:

- Convenient online submission

- Thorough peer review

- No space constraints or color figure charges

- Immediate publication on acceptance

- Inclusion in PubMed, CAS, Scopus and Google Scholar

- Research which is freely available for redistribution 